\title{
Modification of gastric cancer risk associated with proton pump inhibitors by aspirin after Helicobacter pylori eradication
}

\author{
Ka Shing Cheung ${ }^{1}$ and Wai K. Leung ${ }^{1}$ \\ ${ }^{1}$ Department of Medicine, The University of Hong Kong, Queen Mary Hospital, Pok Fu Lam, Hong Kong \\ Correspondence to: Wai K. Leung, email: waikleung@hku.hk \\ Keywords: aspirin; PPI; H. pylori; gastric adenocarcinoma; triple therapy \\ Received: August 09, $2018 \quad$ Accepted: October 23, $2018 \quad$ Published: December 11, 2018
}

Copyright: Cheung et al. This is an open-access article distributed under the terms of the Creative Commons Attribution License 3.0 (CC BY 3.0), which permits unrestricted use, distribution, and reproduction in any medium, provided the original author and source are credited.

\section{ABSTRACT}

Aim: Although proton pump inhibitors (PPIs) can prevent aspirin-induced upper gastrointestinal bleeding, a clinical dilemma exists as long-term use of PPI may also increase the risk of gastric cancer even after Helicobacter pylori (HP) eradication. We aimed to investigate the potential interaction between aspirin and PPIs on GC risk in patients who have HP eradicated.

Results: Of the 63,397 HP eradicated subjects (median follow-up 7.6 years), 153 (0.24\%) developed GC. PPIs were associated with a higher GC risk among non-aspirin users (aHR: 3.73, 95\% CI:2.11-6.60) but not among aspirin users (aHR: 0.35, 95\% CI:0.04-2.74).

Materials and Methods: This is a post-hoc analysis based on a previously published territory-wide retrospective cohort study on the potential risk of PPIs on GC. Adults who had received an outpatient prescription of clarithromycin-based triple therapy for HP between 2003 and 2013 were identified. The adjusted hazard ratio (aHR) of GC with PPIs, stratified according to aspirin use, was calculated by Cox model with propensity score adjustment of other covariates.

Conclusions: The potential harmful effects of PPIs on GC development appear to be limited to non-aspirin users. Co-prescription of PPIs is therefore recommended for HP-eradicated patients who are at risk of aspirin-induced UGIB.

Gastric cancer is the fifth commonest cancer and the third leading cause of cancer-related death [1]. Although Helicobacter pylori (H. pylori) infection is one of the major risk factors of gastric cancer [2], H. pylori eradication could only reduce the risk of gastric cancer by around $40 \%[3,4]$. We have previously shown that aspirin, one of the most widely available chemopreventive agents, is associated with a reduced risk of gastric cancer in H. pylori-eradicated patients (hazard ratio [HR]: 0.30; 95\% confidence interval [CI]: $0.15-0.61$ ) [5]. However, aspirin increases the risk of upper gastrointestinal bleeding (UGIB), with an incidence rate of 0.91 cases per 1000 person-years in a recent population-based study from the United Kingdom [6]. It is suggested that aspirin users at high risk of UGIB (e.g. prior history of peptic ulcer disease, advanced age, concomitant usage of ulcerogenic agents) should be co-prescribed with proton pump inhibitors (PPIs) [7]. However, as long-term use of PPIs is associated with an increased gastric cancer risk even after
H. pylori eradication (HR: 2.44; 95\% CI 1.42-4.20) [8], it remains a major clinical dilemma whether PPIs should be co-prescribed with aspirin to reduce the risk of UGIB.

To address this unresolved issue, we have investigated the potential interaction of aspirin with PPIs on the risk of gastric cancer after $H$. pylori eradication, based on our previously described cohort who had received clarithromycin-based triple therapy $(n=$ $63,397)[8]$. The data were retrieved from the territorywide electronic medical records, known as Clinical Data Analysis and Reporting System (CDARS), of the Hong Kong Hospital Authority. A significant number of populated-based studies have been published using this electronic healthcare database $[9,10]$. We hypothesized that the harmful effect of PPIs (in terms of gastric cancer risk) could be negated by the usage of low-dose aspirin among $H$. pylori-eradicated subjects.

In the primary analysis, we used propensity score (PS) regression adjustment with trimming of the extreme 
Table 1: Association between proton pump inhibitors and gastric cancer for the whole cohort and according to aspirin usage

\begin{tabular}{|c|c|c|c|c|c|c|c|c|c|}
\hline \multicolumn{10}{|c|}{ Whole cohort } \\
\hline & \multicolumn{3}{|c|}{$\begin{array}{l}\text { Multivariable analysis } \\
(n=63397, \mathrm{GC}=153)\end{array}$} & \multicolumn{3}{|c|}{$\begin{array}{l}\text { PS adjustment without trimming } \\
(n=63397, G C=153)\end{array}$} & \multicolumn{3}{|c|}{$\begin{array}{l}\text { PS adjustment with trimming }(n= \\
57057, \mathrm{GC}=139)\end{array}$} \\
\hline & HR & $95 \% \mathrm{CI}$ & $p$-value & HR & $95 \% \mathrm{CI}$ & $p$-value & HR & $95 \% \mathrm{CI}$ & $p$-value \\
\hline $\begin{array}{l}\text { Non-PPI } \\
\text { use }\end{array}$ & Ref & - & - & Ref & - & - & Ref & - & - \\
\hline PPI use & 2.19 & $\begin{array}{ll}1.31- \\
3.66\end{array}$ & 0.003 & 2.14 & $\begin{array}{l}1.27 \\
3.58 \\
\end{array}$ & 0.004 & 2.44 & $\begin{array}{l}1.42 \\
4.20\end{array}$ & 0.002 \\
\hline \multicolumn{10}{|c|}{ Non-aspirin use } \\
\hline & \multicolumn{3}{|c|}{$\begin{array}{l}\text { Multivariable analysis } \\
(n=54432, \mathrm{GC}=133)\end{array}$} & \multicolumn{3}{|c|}{$\begin{array}{l}\text { PS adjustment without trimming } \\
(n=54432, G C=133)\end{array}$} & \multicolumn{3}{|c|}{$\begin{array}{l}\text { PS adjustment with trimming }(n= \\
48988, G C=115)\end{array}$} \\
\hline & HR & $95 \% \mathrm{CI}$ & $p$-value & HR & $95 \% \mathrm{CI}$ & $p$-value & HR & $95 \% \mathrm{CI}$ & $p$-value \\
\hline $\begin{array}{l}\text { Non-PPI } \\
\text { use }\end{array}$ & Ref & - & - & Ref & - & - & Ref & - & - \\
\hline PPI use & 3.27 & $\begin{array}{l}1.93- \\
5.53\end{array}$ & $<0.001$ & 3.38 & $\begin{array}{l}1.99 \\
5.75\end{array}$ & $<0.001$ & 3.73 & $\begin{array}{ll}2.11 & - \\
6.60 & - \\
\end{array}$ & $<0.001$ \\
\hline \multicolumn{10}{|c|}{ Aspirin use } \\
\hline & \multicolumn{3}{|c|}{$\begin{array}{l}\text { Multivariable analysis } \\
(n=8965, \mathrm{GC}=20)\end{array}$} & \multicolumn{3}{|c|}{$\begin{array}{l}\text { PS adjustment without trimming } \\
(n=8965, \mathrm{GC}=20)\end{array}$} & \multicolumn{3}{|c|}{$\begin{array}{l}\text { PS adjustment with trimming }(n= \\
8067, G C=16)\end{array}$} \\
\hline & HR & $95 \% \mathrm{CI}$ & $p$-value & HR & $95 \% \mathrm{CI}$ & $p$-value & HR & $95 \% \mathrm{CI}$ & $p$-value \\
\hline $\begin{array}{l}\text { Non-PPI } \\
\text { use }\end{array}$ & Ref & - & - & Ref & - & - & Ref & - & - \\
\hline PPI use & 0.53 & $\begin{array}{ll}0.12 & - \\
2.37 & -\end{array}$ & 0.402 & 0.52 & $\begin{array}{l}0.11 \\
2.34\end{array}$ & 0.392 & 0.35 & $\begin{array}{ll}0.04 & - \\
2.74 & \end{array}$ & 0.318 \\
\hline
\end{tabular}

Non-PPI use were defined as less than weekly use of PPIs; PPI use was defined as at least weekly use of PPIs. Abbreviations: PS, propensity score; GC, gastric cancer; HR, hazard ratio; 95\% CI, 95\% confidence interval; PPI, proton pump inhibitor.

PS strata in the Cox proportional hazards model to derive the adjusted HR of gastric cancer with PPI use. PS was the probability of being given PPIs conditional on other covariates including age of receiving $H$. pylori eradication therapy, sex, smoking, alcohol use, comorbidities (prior peptic ulcer disease, diabetes mellitus, hypertension, dyslipidemia, obesity, ischemic heart disease, atrial fibrillation, congestive heart failure, stroke, chronic renal failure and cirrhosis) and concomitant usage of medications (namely, aspirin, non-steroidal antiinflammatory drugs, cyclooxygenase-2 inhibitors, statins, metformin, clopidogrel and histamine-2 receptor antagonists). We constructed 20 categories of 5\% each for the PS distribution and patients in the first and $20^{\text {th }}$ PS strata were trimmed to further reduce biases. Sensitivity analyses were performed by PS regression adjustment without trimming and a multivariable Cox regression.

The median age of this cohort at the time of receiving $H$. pylori eradication therapy was 54.7 years (IQR: 46.0 - 65.4 years), and $46.5 \%$ were men. With a median follow-up of 7.6 years (IQR: 5.1 - 10.3 years) totaling 483,260 person-years, 153 (0.24\%) patients developed gastric cancer after receiving $H$. pylori eradication therapy. Table 1 shows the gastric cancer risk with PPI use for the whole cohort and according to the usage of aspirin. For the whole cohort, the PS adjusted HR of gastric cancer with PPI use was 2.44 (95\% CI: 1.42 4.20). Among non-aspirin users, the harmful effect of PPIs appeared to be even larger (HR 3.73; 95\% CI: 2.11 - 6.60). PPI use, however, was not associated with an increase in gastric cancer risk among aspirin users (HR 0.35; 95\% CI: 0.04 - 2.74). The test for subgroup difference indicates a significant difference between the association of PPIs with gastric cancer in aspirin and non-aspirin users ( $p$-value for interaction: 0.010).

In conclusion, we observed in this cohort of $H$. pylori-eradicated subjects that aspirin use appears to negate the potential harmful effect of PPIs on gastric cancer development. Hence, co-prescription of PPIs should still be recommended in $H$. pylori-eradicated patients at risk of aspirin-related UGIB without the concern of an increased gastric cancer risk.

\section{Author contributions}

Dr. Ka Shing Cheung was involved with study concept and design; analysis and interpretation of data; drafting of manuscript; and approval of the final version of the manuscript. Dr Wai K Leung were involved with the study concept and design; analysis and interpretation of data; drafting of manuscript; critical revision of the manuscript for important intellectual content; study 
supervision; and approval of the final version of the manuscript.

\section{CONFLICTS OF INTEREST}

There are no competing interests.

\section{FUNDING SUPPORT}

WKL has received honorarium for attending advisory board meetings of Takeda and Abbott Laboratories.

\section{REFERENCES}

1. World Health Organisation. Cancer Fact Sheets: Stomach Cancer. http://gco.iarc.fr/today/fact-sheetscancers? cancer $=5 \&$ type $=0 \&$ sex $=0$

2. Helicobacter and Cancer Collaborative Group. Gastric cancer and Helicobacter pylori: a combined analysis of 12 case control st udies nested within prospective cohorts. Gut. 2001; 49:347-53.

3. Cheung KS, Leung WK. Risk of gastric cancer development after eradication of Helicobacter pylori. World J Gastrointest Oncol. 2018; 10:115-23.

4. Lee YC, Chiang TH, Chou CK, Tu YK, Liao WC, Wu MS, Graham DY. Association Between Helicobacter pylori Eradication and Gastric Cancer Incidence: A Systematic Review and Meta-analysis. Gastroenterology. 2016; 150:1113-1124.e5.

5. Cheung KS, Chan EW, Wong AY, Chen L, Seto WK, Wong IC, Leung WK. Aspirin and Risk of Gastric Cancer After Helicobacter pylori Eradication: A Territory-Wide Study. J Natl Cancer Inst. 2018; 110:743-49.
6. Cea Soriano L, Lanas A, Soriano-Gabarró M, García Rodríguez LA. Incidence of Upper and Lower Gastrointestinal Bleeding in New Users of Low-Dose Aspirin. Clin Gastroenterol Hepatol. 2018 Jun 14. [Epub ahead of print].

7. Lanza FL, Chan FK, Quigley EM, and Practice Parameters Comm ittee of the American College of Gastroenterology. Guidelines for prevention of NSAID-related ulcer complications. Am J Gastroenterol. 2009; 104:728-38.

8. Cheung KS, Chan EW, Wong AY, Chen L, Wong IC, Leung WK. Long-term proton pump inhibitors and risk of gastric cancer development after treatment for Helicobacter pylori: a population-based study. Gut. 2018; 67:28-35.

9. Cheung KS, Seto WK, Fung J, Mak LY, Lai CL, Yuen MF. Epidemiology and natural history of Wilson's disease in the Chinese: A territory-based study in Hong Kong between 2000 and 2016. World J Gastroenterol. 2017; 23:7716-26.

10. Cheung KS, Seto WK, Fung J, Lai CL, Yuen MF. Epidemiology and Natural History of Primary Biliary Cholangitis in the Chinese: A Territory-Based Study in Hong Kong between 2000 and 2015. Clin Transl Gastroenterol. 2017; 8:e116. 